\title{
SEQUÊNCIA DIDÁTICA DE GÊNERO TEXTUAL: UMA FERRAMENTA DE ENSINO DA ESCRITA NO PROCESSO DE ALFABETIZAÇÃO
}

\author{
F. S. S. VIEIRA ${ }^{1}$ e A. S. M. APARÍCIO
Universidade de São Caetano do Sul
fabianavieira@scseduca.com.br ${ }^{1}$ \\ Submetido em 11/12/2017 e aceito em 26/08/2019 \\ DOI: $10.15628 /$ holos.2020.6664
}

\section{RESUMO}

Neste artigo, descrevemos e analisamos dados de uma pesquisa mais ampla em que buscamos investigar o processo de construção de uma Sequência Didática (SD) com o gênero "carta ao autor", em uma turma de 1‥ ano, com vistas ao desenvolvimento das capacidades de linguagem dos aprendizes. Como referencial teórico do trabalho, adotamos as contribuições dos estudos do grupo de didática das línguas da Universidade de Genebra (SCHNEUWLY; DOLZ, 2004; DOLZ; GAGNON; DECANDIO, 2010) e de pesquisadores brasileiros (NASCIMENTO, 2014; APARÍCIO; ANDRADE, 2016) sobre a SD de gêneros textuais com objetivo de produzir conhecimentos que contribuam para o ensino da língua materna. O método da pesquisa é de cunho colaborativo-intervencionista, tendo em vista que a SD foi construída colaborativamente pela pesquisadora e professora regente da turma de 1ㅇ. ano em que foi realizada a intervenção. Seguindo a abordagem qualitativa de pesquisa, os dados gerados e analisados foram: registros de diário de campo da elaboração da $\mathrm{SD}$, gravações em áudio e vídeo das aulas e produções textuais dos alunos. A análise dos dados que selecionamos para este trabalho indica que a ferramenta SD contribuiu para avanços significativos no desenvolvimento das capacidades de linguagem dos alunos em processo de alfabetização.

PALAVRAS-CHAVE: Sequência didática de gêneros textuais, Alfabetização, Capacidades de linguagem.

\section{DIDACTIC SEQUENCE OF TEXTUAL GENDER: A TEACHING TOOL IN THE LITERACY PROCESS}

\begin{abstract}
In this article, we describe and analyze data from a broader research which we seek to investigate the process of constructing a Didactic Sequence (DS) with the genre "letter to author", in a 1st grade class, aiming the development of language skills of the students. As theoretical reference of the work, studies of the didactics group of the languages from the University of Geneva were adopted as contributions (SCHNEUWLY, DOLZ, 2004; DOLZ, GAGNON, DECANDIO, 2010) and Brazilian researchers (NASCIMENTO, 2014; APARÍCIO; ANDRADE, 2016) on a DS of textual genres to produce knowledge that will contribute to teach the
\end{abstract}

mother language. The method of research is collaborative-interventionist, considering that DS was developed by the researcher and teacher of the 1st grade class, where was made the study. Following a qualitative research approach, the genareted and analyzed data was: field diary records of DS elaboration, audio and video recordings and textual students's productions. The selected analysed data indicates that the DS tool contributed significantly to students advances in developing language skills in the literacy process.

KEYWORDS: Didactic sequence of textual genres, Literacy, Language abilities. 


\section{APRESENTAÇÃO}

O ensino da língua materna no Brasil vem sofrendo transformações, sobretudo a partir da publicação dos Parâmetros Curriculares Nacionais de Língua Portuguesa (PCN), que introduzem a noção de gêneros textuais orais e escritos, articulada à noção de texto e de letramento, como objeto de ensino da leitura e da escrita na escola. Sob essa perspectiva, no contexto da alfabetização, a orientação dos PCN é que o professor incorpore em sua prática de sala de aula a escrita e leitura de diferentes gêneros textuais, oferecendo aos alunos materiais escritos diversos, mesmo que ainda não leiam e escrevam convencionalmente.

Em outras palavras, para garantir aos alunos o aumento de seu repertório de conhecimento sobre a escrita, é preciso a vivência com diferentes situações de uso social da língua por meio do trabalho com gêneros textuais em atividades significativas de leitura e de escrita, favorecendo o processo de alfabetização (TEBEROSKY e COLOMER, 2003). Contudo, as práticas pedagógicas de alfabetização ainda têm dado mais enfoque à aquisição da escrita como um código, centrando-se na memorização e associação das letras aos sons, isto é, "insistem em procedimentos mecânicos, descontextualizados e pouco significativos". (COLELLO, 2014, p. 2).

Um aspecto essencial para a transformação dessas práticas é a compreensão da língua como prática discursiva e dialógica (BAKHTIN, 2003) e a compreensão de ensino de língua em que "quem fala ou escreve é um sujeito que, em determinado contexto histórico, em determinada situação pragmática de aprendizagem, interage com um interlocutor, também ele um sujeito, e o faz levado por um objetivo, um desejo, uma necessidade de interação". (SOARES, 1999, p. 61-62).

Outro aspecto que se apresenta fundamental para uma nova abordagem de ensino e aprendizagem da língua é o planejamento das modalidades organizativas que, segundo Lerner (2002), são formas de organizar os conteúdos no tempo didático que superam a fragmentação do conhecimento e que auxiliam o professor a analisar o percurso de aprendizagem de cada aluno, identificando o que os alunos já sabem para planejar atividades e poder realizar intervenções adequadas de acordo com os diferentes níveis de conhecimento da escrita dos alunos e, assim, identificar os avanços.

A "sequência didática de gêneros textuais" (doravante SD) é uma modalidade organizativa proposta para o ensino da língua materna que, em linhas gerais, significa, de acordo com Dolz, Noverraz e Schneuwly (2004, p. 97), "um conjunto de atividades escolares organizadas, de maneira sistemática, em torno de um gênero textual oral ou escrito." Esse dispositivo didático, conforme defendem os autores, ajuda o aluno no domínio de um determinado gênero textual, adequando-se a uma situação comunicativa, com oportunidade de novas práticas de linguagem.

Com base nesses pressupostos, discutimos, neste artigo, resultados de uma pesquisa mais ampla em que buscamos analisar o processo de construção de uma SD com o gênero "carta ao autor", em uma turma de 1‥ ano, com vistas ao desenvolvimento das capacidades de linguagem dos aprendizes.

Primeiramente, apresentamos os pressupostos teóricos que fundamentam a pesquisa, bem como a metodologia e caracterização do contexto da pesquisa. Na sequência, descrevemos o processo de elaboração e desenvolvimento da SD e, por fim, realizamos uma análise das produções textuais e a discussão dos resultados. 


\section{OS GÊNEROS TEXTUAIS NO ENSINO E APRENDIZAGEM DA LÍNGUA MATERNA NO CONTEXTO DA ALFABETIZAÇÃO}

As práticas de ensino no contexto da alfabetização têm sido muito discutidas com vistas a melhorar o domínio da língua materna e as capacidades de linguagem dos alunos. Segundo os PCN:

Se o objetivo é que o aluno aprenda a produzir e interpretar textos, não é possível tomar como a unidade básica de ensino nem a letra, nem a sílaba, nem a palavra, nem a frase que, descontextualizadas, pouco têm a ver com a competência discursiva, que é a questão central. Dentro desse marco, a unidade básica de ensino só pode ser o texto, mas isso não significa que não se enfoquem palavras ou frases nas situações didáticas específicas que o exijam. (BRASIL, 1997, p.29)

No sentido proposto pelo documento, a aprendizagem da língua deve ocorrer em situações contextualizadas, relacionadas a uma situação comunicativa de forma dialógica, cabendo ao professor planejar propostas didáticas com textos de diferentes gêneros e com propósitos diversos para oportunizar aos alunos a vivência em uma perspectiva comunicativa real.

Sendo assim, entendemos que, na alfabetização, aprender a língua escrita é muito mais do que decodificar e associar letras e sons. Essa perspectiva também é defendida pelos estudos da Didática das línguas, área que se preocupa com maneiras de criar as boas condições para a aprendizagem de uma língua (materna ou estrangeira), tendo como foco de análise as práticas de ensino em sala de aula, o desenvolvimento das capacidades de linguagem dos aprendizes, as formas de adequação do ensino às capacidades dos alunos, as ferramentas e dispositivos de ensino. (NASCIMENTO, 2014).

No âmbito dos estudos da Didática de língua materna, pesquisadores do chamado Grupo de Genebra (DOLZ; SCHNEUWLY, 2004; DOLZ; GAGNON; DECÂNDIO, 2010; entre outros) e colaboradores brasileiros (NASCIMENTO, 2014; MACHADO, 2009; GONÇALVES, 2008, entre outros), vêm realizando pesquisas sobre a SD com objetivo de produzir conhecimentos que contribuam para realizar um trabalho, em sala de aula, que faça sentido para os alunos e os levem a construir as habilidades necessárias à produção de textos de um determinado gênero.

A SD proposta por Dolz, Noverraz e Schneuwly (2004), e que desenvolvemos em nossa pesquisa, é composta de quatro etapas principais, conforme ilustra a figura a seguir.

Figura 1 - Esquema da sequência didática

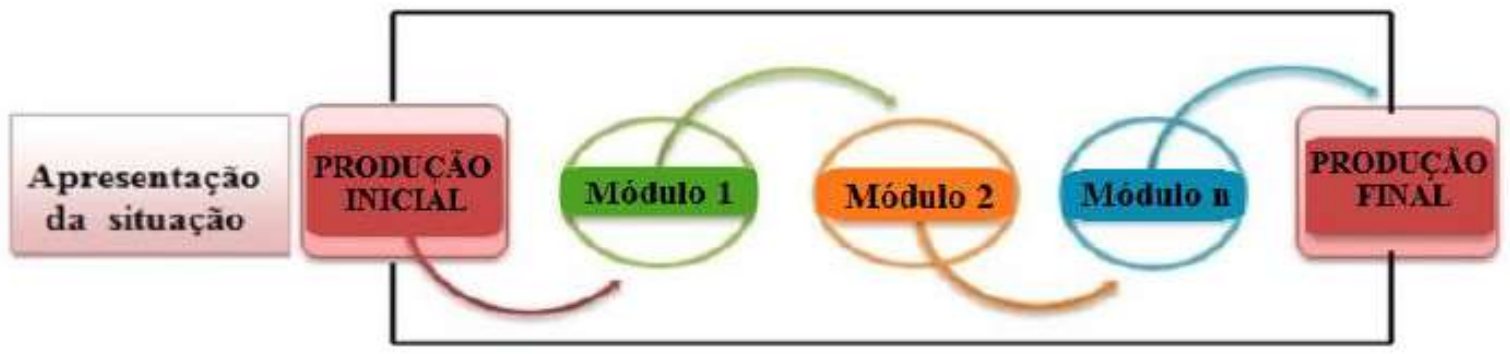

Fonte: Adaptado de Dolz; Noverraz; Schneuwly, (2004, p.83). 
Conforme o esquema acima, a construção da SD se inicia pela apresentação da situação, etapa inicial que tem como objetivo apresentar um projeto de comunicação que será realizado de forma autêntica com os alunos. Nesse momento está a consigna da produção, isto é, comanda realizada, oralmente, pelo professor para orientar sobre o gênero do texto que será produzido e os elementos da situação de produção.

Nessa primeira etapa da SD, segundo os autores genebrinos, é importante que seja apresentado um projeto de comunicação dando propósitos reais e bem detalhados, para que os alunos saibam de maneira explicita qual é o propósito da situação de comunicação que será realizado verdadeiramente na produção final. Além disso, é preciso preparar os conteúdos dos textos que serão produzidos, isto é, fornecer aos alunos informações importantes para o projeto de comunicação em que irão trabalhar, para que os alunos se motivem e se engajem nas atividades.

A segunda etapa da SD, a primeira produção, ocorre após a apresentação da situação de produção. Segundo Dolz, Noverraz e Schneuwly (2004, p.86), "[...] a produção inicial tem um papel central como reguladora da sequência didática, tanto para os alunos quanto para o professor". Para os alunos, essa é a primeira elaboração da produção textual com base nos elementos dados durante a apresentação da situação de comunicação, e permite que os alunos descubram o que sabem e quais são suas dificuldades. É nesse momento, portanto, que os alunos expressam por meio das produções escritas quais são as representações que têm a respeito do gênero e do projeto de comunicação em curso.

Para o professor, a produção inicial seria como uma avaliação diagnóstica das capacidades reais de cada aluno da turma e contribui para o professor saber o que ainda o aluno não aprendeu a respeito de um conteúdo/assunto. Assim, a partir da análise dessa primeira produção, o professor consegue verificar as dificuldades e conhecimentos prévios dos alunos para que identifique situações para intervir, dando base para planejar o desenvolvimento da SD e para delinear as dimensões ensináveis do gênero em um modelo didático que o ajudará acompanhar o processo de aprendizagem dos alunos.

Após a análise da primeira produção, terceiro momento é o desenvolvimento dos Módulos, que são atividades planejadas pelo professor, a partir da análise da produção inicial, em forma de oficinas que possuem objetivos claros e visam ajudar a superar as dificuldades encontradas pelos alunos na produção inicial. O processo de planejamento e desenvolvimento dos módulos é complexo, pois cabe ao professor verificar as aprendizagens e dificuldades dos alunos, avaliando de forma processual e contínua as capacidades de linguagem dos alunos, relacionadas à produção do texto em questão.

Segundo Dolz, Noverraz e Schneuwly (2004), é importante que as atividades dos módulos trabalhem problemas de níveis diferentes para que ajudem os alunos refletirem a respeito das características da situação de produção e os diferentes aspectos que envolvam o gênero como: adequação do texto ao leitor alvo, ao suporte/contexto de circulação do texto, o conteúdo temático do texto, a estrutura e organização das partes do texto, coesão e coerência textual, aspectos gramaticais etc.

Por fim, ao terminar os módulos, os alunos põem em prática os conhecimentos construídos ao longo da SD, recebem a primeira produção e são convidados a reescrevê-la, no momento da realização da Produção Final. Nesta última etapa, os alunos têm a oportunidade de colocar em prática o que aprenderam durante os módulos, avaliar o próprio progresso e controlar o seu próprio comportamento de produtor de texto durante a realização da revisão e reescrita da produção inicial. 
É nesse momento que o professor, utilizando a produção inicial e a produção final, pode verificar as aprendizagens dos alunos e também planejar a continuidade do trabalho, retomando aspectos que não foram apreendidos pelos alunos.

Em síntese, o dispositivo SD oferece ao professor maiores possibilidades de conhecer as capacidades e dificuldades dos alunos. $\mathrm{E}$, ao aluno, permite que veja o próprio texto como um objeto a ser retrabalhado e revisto, entendendo a reescrita como parte do processo de produção textual, possibilita-lhe refletir sobre a própria língua e, consequentemente, aprimorar a sua escrita desenvolvendo as capacidades de linguagem. São elas: capacidades de ação (relacionadas ao reconhecimento do contexto de produção do gênero); capacidades discursivas (relacionadas ao reconhecimento da arquitetura textual do gênero) e capacidades linguístico-discursivas (relacionadas ao reconhecimento e utilização de recursos linguísticos essenciais para a compreensão do gênero). Cabe salientar que as três capacidades são interligadas, segundo Dolz e Schneuwly (2004), uma capacidade não age sozinha, pois são mobilizadas simultaneamente pelo aprendiz.

Dessa maneira, defendemos que o trabalho com a SD é essencial na alfabetização, pois desde o momento em que o aluno começa a escrever seus primeiros textos, contribui para que o professor possa acompanhar e intervir nesse processo de forma mais assertiva. Além disso, o ensino da língua materna visa ao domínio de gêneros textuais, considerados por Schneuwly (2004) como um megainstrumento didático, na medida em que auxiliam no processo ensino e aprendizagem das línguas, ao mesmo tempo em que têm a função de mediar as interações entre os sujeitos e a situação. Em outras palavras, os gêneros auxiliam no processo e no desenvolvimento da linguagem agindo como articuladores das práticas sociais e dos objetos escolares que contribuem para a participação do educando na vida social e comunicativa facilitando e modificando os saberes essenciais para a produção textual no contexto escolar.

\section{METODOLOGIA E CARACTERIZAÇÃO DO CONTEXTO DA PESQUISA}

A abordagem metodológica da pesquisa é qualitativa, de cunho colaborativointervencionista (DAMIANI et al., 2013), tendo a participação desta professora pesquisadora e de uma professora colaboradora.

A pesquisa foi desenvolvida em uma escola municipal de tempo integral da região do Grande ABC paulista, em uma classe de 1‥ ano, nas Oficinas Curriculares de Produção de Texto, na sala da professora colaboradora. O processo de construção da SD de gênero textual foi realizado de forma compartilhada com negociações e tomada de decisões conjuntas, numa ação de parceria entre professora pesquisadora e professora colaboradora.

Os dados gerados em nossa pesquisa, ao longo do trabalho colaborativo na elaboração, desenvolvimento e realização da SD, são constituídos por registros em áudio das falas nos encontros desta professora pesquisadora com a professora colaboradora, gravação em vídeo das aulas por esta pesquisadora, registros reflexivos em diário de campo da própria pesquisadora e as produções escritas realizadas pelos alunos na SD.

Com relação ao contexto da pesquisa é importante destacar que a educação integral foi inicialmente instituída pela Lei de Diretrizes e Bases da educação Nacional (LDBEN/96) que, em seu art.34, § 2으, preconiza a progressiva implantação do ensino em tempo integral, a critério dos sistemas de ensino. No município em questão, as escolas de tempo integral procuram garantir o que está previsto na LDBEN/96, no que se refere ao ensino integral, para a promoção de formação para a vivência de novas experiências, que articulem diferentes disciplinas e 
transversalidade de temas para o desenvolvimento das habilidades que auxiliem no aprendizado em sala de aula.

As Oficinas Curriculares de Produção de Texto, focalizadas na pesquisa, fazem parte da matriz curricular tendo como objetivo desenvolver competências e habilidades de leitura e escrita, sendo realizadas em duas horas/aulas semanais com a duração de 40 minutos cada, totalizando uma hora e trinta minutos por semana sendo as essas duas aulas seguidas no mesmo dia. Essas Oficinas buscam contribuir com a plena alfabetização dos educandos, em uma perspectiva de formação do sujeito que utiliza a leitura e a escrita para comunicar-se com o mundo em que vive, mergulhando no mundo letrado de forma a compreendê-lo e interpretálo. No início do ano letivo, são definidos com as professoras responsáveis pela oficina quais gêneros textuais serão trabalhados ao longo do ano, distribuídos por trimestre.

Com o início da constituição do trabalho colaborativo que estabelecemos no desenvolvimento desta pesquisa, o Planejamento do segundo trimestre, foi elaborado incluindo como base de estudo o texto "Sequência didática para o oral e a escrita: apresentação de um procedimento" (Dolz; Noverraz; Schneuwly, 2004). Os conteúdos previstos foram: poemas, bilhetes, quadrinhas, convite e também o trabalho com a leitura do livro paradidático: "Tutuli em: que barulho é esse papai" do autor Marcelo Loro adotado para as turmas do 10 . ano, o qual desencadeou a SD do gênero "carta ao autor".

Resumidamente, o livro trata de uma história inspirada no filho do próprio autor, um menino chamado Tutuli que ao escutar barulhos sentia medo e sempre perguntava ao papai: Que barulho é esse, papai? e seu pai sempre o ajudava a desvendar os mistérios de cada barulho.

Com a preocupação de criar um clima favorável à leitura do livro e despertar o interesse e a curiosidade dos alunos, a professora, em uma roda de conversa, levou as crianças a realizarem inferências com a observação da capa do livro, levantando as hipóteses dos alunos sobre o que o livro pode tratar. Com essa exploração, os alunos identificaram algumas informações importantes como: título da história, nome do autor e as ilustrações.

Em outro momento, a professora realizou a leitura em voz alta e cada aluno acompanhava a leitura com seu próprio livro. Ao término da história, as crianças relataram suas impressões e registraram a parte que mais gostaram por meio de desenho. Com base na história, as crianças identificaram que a personagem "Tutuli" tinha muitos medos e na roda de conversa foi realizada uma atividade em que foram listados os medos dos alunos. Nessa proposta, a professora foi escriba e essa lista coletiva foi fixada na parede na sala de aula.

Durante as aulas, as crianças observaram que, na última página do livro, havia uma fotografia da família do autor e, quando a professora realizou a leitura das informações da vida do autor, elas ficaram interessadas ao saber que o livro foi inspirado no seu filho Arthur (conhecido no livro como Tutuli) e que também tinha uma filha chamada Sarita. Nesse momento, surgiram alguns questionamentos pelos alunos: se o "Tutuli" ainda tinha medos, quando seriam os próximos lançamentos dos livros indicados no fim do livro, entre outros.

Com a observação desse interesse dos alunos, junto com a professora colaboradora discutimos e decidimos que o gênero trabalhado na SD seria "Carta ao autor", por partir de uma situação de comunicação real e do interesse das crianças em se comunicar com o autor Marcelo Loro. Dessa forma, daríamos continuidade ao trabalho que já estava sendo realizado com a leitura do livro: "Tutuli em: que barulho é esse papai?", motivando os alunos a produzir seus próprios textos, a partir de uma situação real de comunicação em ambiente escolar. A partir dessa escolha, criamos o Projeto chamado "Cartas ao Autor" (nome inclusive sugerido 
pela professora colaboradora), a partir do qual desenvolvemos a SD, cujas etapas serão descritas no item a seguir.

Cabe destacar que a turma do 1‥ ano é composta por 24 alunos e no início do segundo semestre letivo, momento em que iniciamos a SD, a maioria dos alunos se encontrava entre as hipóteses silábico-alfabética e alfabética, isto é, já compreendiam o funcionamento do sistema de escrita alfabética, representando em sua escrita as unidades menores da pauta sonora fonemas- mesmo que sem a correspondência ortográfica.

\section{ELABORAÇÃO, DESENVOLVIMENTO E REALIZAÇÃO DA SD DO GÊNERO CARTA AO AUTOR}

De acordo com o grupo de didática das línguas da Universidade de Genebra, uma ação importante do professor, anterior à elaboração da SD, é a construção do modelo didático do gênero, visto como uma ferramenta relevante para o professor planejar, criar, organizar e orientar o ensino da produção textual com auxílio do dispositivo SD.

Para Aparício e Andrade (2016), essa é uma tarefa muito complexa, que exige do professor o domínio dos conteúdos que serão ensinados para melhor seleção de aspectos do gênero a ser trabalhado, tais como:

- a literatura a respeito do gênero, buscando os saberes teóricos a seu respeito, consultando estudos que já o investigaram e analisaram;

- as práticas sociais de referência, de uso do gênero, que emergem em diferentes situações reais de comunicação, observando e examinando, em vários textos do mesmo gênero: as características da situação de produção (quem são o emissor e receptor e seu papel social, a quem se dirige, local e momento de produção e circulação, suporte, objetivo, tipo de linguagem, etc.), os conteúdos típicos do gênero e as diferentes formas de mobilizar esses conteúdos, o estilo (características linguísticas e seus efeitos), sequências textuais e as tipologias do discurso predominantes, mecanismos de coesão e coerência, escolhas lexicais;

- As capacidades de linguagem dos alunos, bem como suas necessidades e possibilidades de aprendizagem de acordo com a faixa etária, o nível de ensino;

- As práticas escolares, as situações de ensino/aprendizagem vivenciadas com o estudo dos gêneros, enfim, as formas de trabalho já realizadas no contexto escolar, seja por professores mais experientes ou por resultados de investigação do campo da didática de língua materna;

- As orientações dos documentos oficiais - atualmente, para a implementação de seus currículos, secretarias municipais e estaduais têm produzido bons materiais para subsidiar o trabalho do professor com os gêneros textuais (APARICIO; ANDRADE, 2016, p.48-49).

A partir da realização dessas tarefas, elaboramos uma grade de análise das produções dos alunos, com base em Aparício; Andrade, (2014, p.273), conforme o Quadro 1 a seguir.

Quadro 1: Grade de análise do gênero "Carta ao autor" Definição - A carta ao autor pode ser vista como uma troca de correspondência entre leitor e 
autor, sendo uma maneira do leitor expressar suas opiniões, sugestões, críticas, elogios e perguntas.

Relevância - é um gênero textual em que o aluno pode participar ativamente expressando suas ideias, com uma função social real, vivenciando na escola uma prática social.

Finalidade - Interação dos leitores com o autor do livro para expressar suas opiniões, expressões, curiosidades, etc.

\section{1- Contexto de produção}

a) Remetente - Assumiu sua voz na escrita da carta? Em primeira pessoa do singular ou do plural?

b) Destinatário - Produziu o texto adequado ao destinatário e com a linguagem adequada?

c) Objetivo - Produziu o texto adequado aos objetivos?

d) Circulação/Suporte- Produziu um texto adequado ao contexto de circulação?

\section{2- Conteúdos temáticos}

a) Assunto da carta é preciso?

b) Assunto é coerente e pertinente?

c) Apresentação do assunto possui uma sequência lógica?

\section{3-Planificação/estrutura composicional do texto}

a) Se a organização dos elementos da carta estão adequadas? (Data e lugar, destinatário, saudação inicial, assunto, saudação final, assinatura do emissor)

b) Há conexão entre as partes?

c) O texto aproxima-se da estrutura do gênero carta?

d) Usa os recursos adequados ao gênero carta?

\section{4-Textualização/elementos linguísticos e gramaticais}

a) Organizou o texto com as convenções gráficas apropriadas?

b) Possui alinhamento e direção de escrita?

c) Apresenta espaçamento entre as palavras?

d) Faz emprego do parágrafo?

e) Possui as noções básicas de pontuação?

\section{5- Estilo/Autoria}

a) Apresenta traços próprios na escrita da carta?

b) Expressa seu olhar pessoal sobre algo que lhe chamou a atenção?

Fonte: Quadro adaptado de Aparício; Andrade (2014, p.273),

A consideração de todos esses aspectos ajudou-nos a definir melhor os objetivos do ensino do gênero de acordo com o nível de aprendizagem dos alunos, oferecendo indícios do que poderá ser explorado na SD. Nesse sentido, os modelos didáticos de gêneros, funcionando como uma base de dados para a construção da SD tem como objetivo orientar o professor nas práticas do ensino da língua e ajudá-lo a acompanhar o desenvolvimento das capacidades de linguagem dos alunos (DOLZ; GAGNON; DECANDIO, 2010).

Após esse trabalho, realizado colaborativamente com a professora, planejamos a apresentação da situação, isto é, a situação de comunicação, a consigna que apresentamos aos alunos para a primeira produção da carta ao autor, conforme informações a seguir.

Consigna da produção inicial: Produção manuscrita de uma carta para o autor do livro "Tutuli em: que barulho é esse papai?", a ser entregue em mãos, quando o autor vier visitar a escola.

- Enunciador: alunos do 1ํ ano dos anos iniciais 
- Destinatário: autor Marcelo Loro

- Objetivos: Interagir com o autor, por meio de carta manuscrita, expressando suas ideias, opiniões, indagações e sugestões ao autor.

- Lugar de produção e de circulação da produção: Produção realizada na escola a ser entregue em mãos ao autor.

Essas foram, então, as informações da primeira etapa da SD, quando, na apresentação da situação de comunicação, foi feita uma roda de conversa com os alunos, em que foram levantados alguns conhecimentos prévios sobre o gênero carta, com as seguintes perguntas: Como vocês pensam que é uma carta? Como será que tenho que escrever para o autor? 0 que eu preciso escrever na minha carta? E as seguintes orientações: vocês vão pensar e escrever do melhor jeito como acham que é a escrita de uma carta; é muito importante que vocês escrevam e leiam o que estão escrevendo.

Após a apresentação da situação, os alunos realizaram a produção inicial da carta ao autor. Com base na grade de análise (Quadro 1), verificamos que alguns alunos conheciam superficialmente este gênero, outros não, mas todos foram capazes de escrever mesmo sem apresentar todas as características do gênero carta, cada aluno produziu de acordo com as capacidades de linguagem de que já dispunham. Consideramos importante esse momento, pois os alunos expressaram por meio de suas produções escritas quais são as representações que têm a respeito do gênero e do projeto de comunicação em curso.

Assim, essa primeira produção funcionou como uma avaliação diagnóstica em que pudemos verificar quais as dificuldades e conhecimentos dos alunos para planejarmos as atividades a serem desenvolvidas nos módulos da SD, com a finalidade de ampliar e desenvolver as capacidades de linguagem dos alunos.

No quadro a seguir, apresentamos resumidamente as atividades diversificadas e adaptadas às particularidades da turma do $1 \cong$ ano.

Quadro 2: Sinopse dos módulos realizados na SD

\begin{tabular}{|c|c|c|}
\hline Atividades realizadas em cada módulo & $\begin{array}{l}\text { Objetivos específicos dos } \\
\text { módulos }\end{array}$ & $\begin{array}{l}\text { Tempo: } \\
40 \text { minutos } \\
\text { cada oficina }\end{array}$ \\
\hline $\begin{array}{l}\text { Módulo } 1 \text { - Comparação entre bilhete (gênero } \\
\text { trabalhado no trimestre anterior) e carta. } \\
\text { Atividade realizada a partir da observação de } \\
\text { variados textos dos dois gêneros, em que os } \\
\text { alunos foram provocados a expor suas ideias e } \\
\text { questionamentos. } \\
\text { Também foi realizada em sala de aula a leitura do } \\
\text { livro "O carteiro chegou", enfatizando o gênero } \\
\text { carta. }\end{array}$ & $\begin{array}{l}\text { - Identificar a diferença } \\
\text { entre os elementos da } \\
\text { escrita de um bilhete e uma } \\
\text { carta. } \\
\text { - Reconhecer a função da } \\
\text { carta no contexto da } \\
\text { história "O carteiro } \\
\text { chegou". }\end{array}$ & 2 Oficinas \\
\hline $\begin{array}{l}\text { Módulo } 2 \text { - Roda de conversa para retomada das } \\
\text { discussões sobre gênero carta e, em seguida, uso } \\
\text { da lousa digital para apresentação de slides com } \\
\text { as características do gênero apontadas pelos }\end{array}$ & $\begin{array}{l}\text { - Reconhecer a organização } \\
\text { das partes e dos elementos } \\
\text { da carta (Data e lugar, }\end{array}$ & \\
\hline
\end{tabular}




\begin{tabular}{|c|c|c|}
\hline $\begin{array}{l}\text { alunos e sistematizadas pela professora. } \\
\text { Logo após a apresentação, a professora distribuiu } \\
\text { aos alunos diferentes tipos de cartas (pessoal, de } \\
\text { leitor, comercial, etc), para que realizassem a } \\
\text { leitura em duplas. } \\
\text { Por fim, foi realizada a escrita de uma carta } \\
\text { coletiva em que o professor foi escriba. O desafio } \\
\text { era realizar a escrita de uma carta coletiva ao } \\
\text { autor, considerando as características da carta } \\
\text { sistematizadas nos slides. A proposta era que os } \\
\text { alunos discutissem a melhor forma expressar o } \\
\text { que a classe, de forma coletiva, gostaria de falar } \\
\text { para o autor. }\end{array}$ & $\begin{array}{l}\text { destinatário, saudação } \\
\text { inicial, assunto, saudação } \\
\text { final, assinatura). } \\
\text { - Perceber as características } \\
\text { recorrentes desse gênero } \\
\text { em vários tipos de carta. } \\
\text { - Produzir } \\
\text { colaborativamente uma } \\
\text { carta coletiva ao autor } \\
\text { fazendo uso dos aspectos } \\
\text { discutidos na aula. }\end{array}$ & 4 Oficinas \\
\hline $\begin{array}{l}\text { Módulo } 3 \text { - Produção escrita em duplas } \\
\text { produtivas. Antes da produção, em roda de } \\
\text { conversa, a professora colocou em discussão, o } \\
\text { que poderia ser o conteúdo da carta ao autor: } \\
\text { destacando que os alunos poderiam expressar } \\
\text { seu olhar pessoal sobre algo que lhe chamou a } \\
\text { atenção no livro do autor, como também sobre o } \\
\text { autor. Nessa atividade, as duplas foram formadas } \\
\text { por alunos em diferentes estágios de domínio da } \\
\text { escrita, porém não muito distantes, para que } \\
\text { discutissem colaborativamente sobre o que } \\
\text { gostariam de escrever ao autor e, na sequência, } \\
\text { produzissem a carta em dupla com os } \\
\text { conhecimentos construídos nas aulas anteriores. }\end{array}$ & $\begin{array}{l}\text { - Produzir em duplas uma } \\
\text { carta tendo por referência } \\
\text { o estudo e as discussões } \\
\text { das aulas anteriores. }\end{array}$ & 2 Oficinas \\
\hline $\begin{array}{l}\text { Módulo 4-Leitura e discussão com toda a turma } \\
\text { das cartas produzidas em duplas. Para o } \\
\text { desenvolvimento dessa atividade, todas as cartas } \\
\text { foram digitalizadas e projetadas uma a uma na } \\
\text { lousa digital. A professora ia fazendo a leitura das } \\
\text { produções, com intervenções fazendo } \\
\text { questionamentos referentes às características do } \\
\text { gênero carta e aspectos da escrita convencional, } \\
\text { e os alunos participaram dando sugestões à } \\
\text { dupla autora da produção em questão. Por fim, a } \\
\text { professora elaborou juntamente com os alunos } \\
\text { uma lista de constatações do que foi observado } \\
\text { na leitura e discussão das cartas elaboradas pelas } \\
\text { duplas. }\end{array}$ & $\begin{array}{l}\text { - Analisar as produções com } \\
\text { os alunos e produzir, } \\
\text { colaborativamente, uma } \\
\text { lista de constatações a } \\
\text { partir das descobertas do } \\
\text { que faltou nas produções e } \\
\text { do que acharam } \\
\text { interessante na escrita da } \\
\text { carta ao autor. }\end{array}$ & 4 Oficinas \\
\hline $\begin{array}{l}\text { Módulo } 5 \text { - Escrita individual de uma carta ao } \\
\text { Papai Noel. Como se aproximava o final do ano, a } \\
\text { professora orientou os alunos para a produção } \\
\text { dessa carta, com a consulta da lista de }\end{array}$ & $\begin{array}{l}\text { - Utilizar a lista de } \\
\text { constatações para } \\
\text { produção individual de }\end{array}$ & 2 Oficinas \\
\hline
\end{tabular}


constatações elaborada nas aulas anteriores, uma carta ao Papai Noel. ressaltando que as produções iriam para o mural da escola e depois entregue aos pais no dia da Reunião de pais.

\section{Fonte: Elaborado pelas autoras}

Por fim, ao terminar os módulos, os alunos receberam a primeira produção para analisála e realizar a produção final, colocando em prática o que aprenderam durante os módulos. Feita a produção final, a professora ainda fez intervenções pontuais e individuais quanto aos aspectos da escrita convencional, incentivando o uso do dicionário para que os alunos percebessem a possibilidade de a escrita ser revisitada e até mesmo corrigida. Com isso, permitindo que o próprio aluno veja o texto como um objeto a ser retrabalhado e revisto, possibilitando-lhe refletir sobre a própria língua. Esse momento de releitura, revisão e a refacção do próprio texto é essencial na SD, pois segundo Lerner (2002, p.53),"planejar, textualizar, revisar mais de uma vez [...] são os grandes comportamentos do escritor".

\section{ANÁLISE DAS PRODUÇõES E DISCUSSÕES DOS RESULTADOS}

Para evidenciar contribuições da SD no desenvolvimento das capacidades de linguagem dos alunos de primeiro ano, selecionamos para a análise um exemplo que consideramos representativo da produção inicial e produção final da carta ao autor elaborada por um aluno na SD em questão.

Figura 2: Produção inicial do aluno João ${ }^{1}$

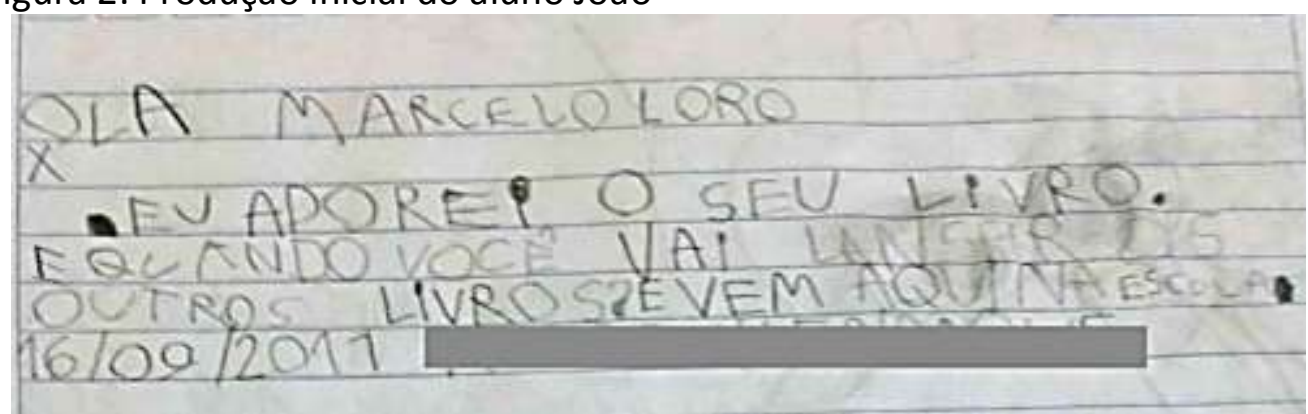

Fonte: Material de arquivo das autoras

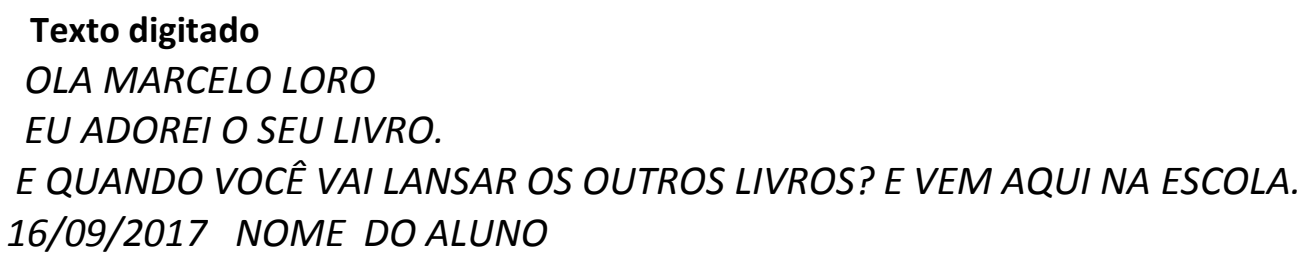

Figura 3: Produção final do aluno João

${ }^{1}$ Para preservar a identidade do aluno utilizamos um nome fictício. 


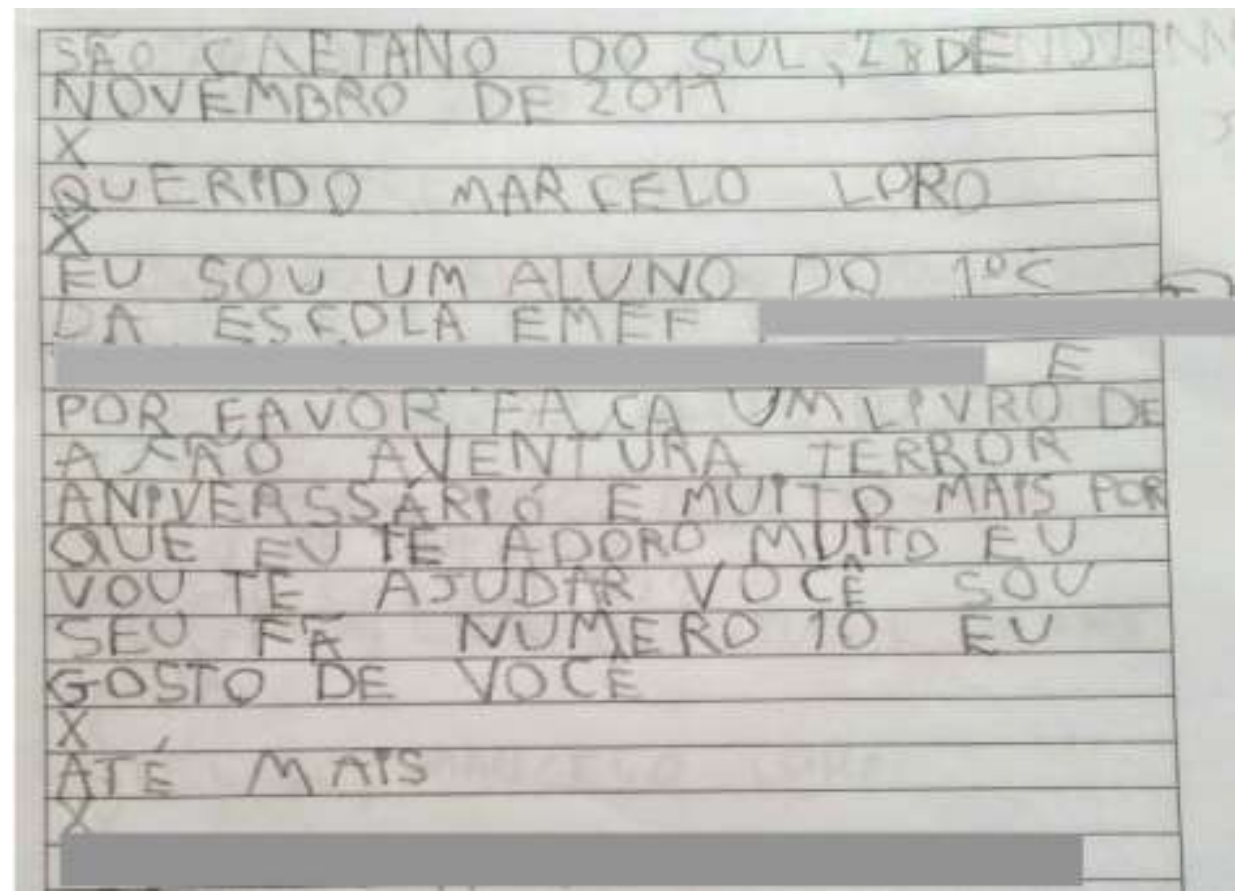

Fonte: Material de arquivo das autoras

Texto digitado:

SÃO CAETANO DO SUL, 28 DE NOVEMBRO DE 2017.

QUERIDO MARCELO LORO

EU SOU UM ALUNO DO 1 ANO C DA ESCOLA E.M.E.F (NOME DA ESCOLA) E POR FAVOR FAÇA UM LIVRO DE AÇÃO, AVENTURA, TERROR, ANIVERSSÁRIO E MUITO MAIS PORQUE EU TE ADORO MUITO EU VOU TE AJUDAR VOCÊ SOU SEU FÃ NÚMERO 10 EU GOSTO DE VOCÊ

ATÉ MAIS

(NOME DO ALUNO)

Para a análise das produções, consideramos os critérios apresentados na grade (Quadro 1), a saber: contexto de produção, conteúdos temáticos, planificação/estrutura composicional do texto, textualização/elementos linguísticos e gramaticais, estilo/autoria.

Quanto ao contexto de produção, como podemos observar na produção inicial (Figura 2), o aluno João atende à consigna proposta pela professora: escrever uma carta manuscrita, que será entregue em mãos ao Marcelo Loro, autor do livro que leram. Na carta, os alunos irão expressar suas ideias, opiniões, indagações e sugestões ao autor.

Com base na consiga, ou seja, na maneira que a professora forneceu a instrução para a realização da atividade, verificamos que João, já produzindo uma escrita alfabética, estabelece a interlocução com o destinatário da carta, fazendo uma saudação inicial, ainda que não seja uma saudação típica do gênero; assume em primeira pessoa a posição de emissor da carta, primeiramente expressando sua percepção da obra do autor (EU ADOREI O SEU LIVRO.) e, por fim, assinando a carta. Além disso, João busca estabelecer a interlocução com o destinatário, fazendo uma pergunta ao autor (QUANDO VOCÊ VAI LANSAR OS OUTROS LIVROS?) e um convite (E VEM AQUI NA ESCOLA), embora não utilize recursos linguísticos adequados para um convite feito a alguém com quem não se tem intimidade, como é o caso do autor. 
Na produção final, no que se refere aos aspectos do contexto de produção, observamos um avanço na escrita de João. Ele atende à consigna e estabelece a interlocução com o destinatário, apresentando-se no início da carta (EU SOU UM ALUNO DO 10 ANO C DA ESCOLA E.M.E.F XXXXX) e fazendo uso de uma linguagem mais adequada tanto na saudação inicial (QUERIDO MARCELO LORO) quanto na solicitação/convite que faz ao autor utilizando "POR FAVOR", marcas linguísticas que dão um maior grau de formalidade, tendo em vista a quem se dirige a carta. Fica nítida, portanto, a ampliação das capacidades de ação de João, ou seja, das capacidades de linguagem relacionadas ao reconhecimento do contexto de produção do gênero.

No que se refere aos conteúdos temáticos, observando as produções inicial e final, também houve uma evolução significativa. Na segunda produção, João tem mais o que dizer ao seu destinatário, inclusive abordando um assunto mais pertinente ao gênero carta ao autor, na medida em que faz solicitações, explicitando seus temas de interesse (POR FAVOR FAÇA UM LIVRO DE AÇÃO, AVENTURA, TERROR, ANIVERSSÁRIO E MUITO MAIS), exprimindo agora, na produção final, o seu apreço pelo autor (PORQUE EU TE ADORO MUITO/SOU SEU FÃ NÚMERO 10/EU GOSTO DE VOCÊ) e ainda se compromete em ajudá-lo (EU VOU TE AJUDAR VOCÊ).

Da mesma forma, em relação à estrutura composicional do gênero carta ao autor, podemos observar que houve um grande avanço na produção final de João. A primeira produção, como podemos verificar na Figura 2, está mais próxima do gênero textual bilhete: saudação ao destinatário, conteúdo curto e assinatura do emissor. Cabe ressaltar que esse foi o último gênero trabalhado em sala de aula, antes da SD, o que demonstra que João tenha utilizado seus conhecimentos sobre o bilhete para escrever a carta ao autor.

Já a produção final apresenta elementos típicos do gênero carta, com organização lógica e espacial do conteúdo e encadeamento entre as partes do texto: local e data completa (SÃO CAETANO DO SUL, 28 DE NOVEMBRO DE 2017.), saudação ao autor com uso de vocativo (QUERIDO MARCELO LORO), assunto (corpo do texto), despedida (ATÉ MAIS) e nome do remetente (assinatura). Com isso, é possível perceber o desenvolvimento das capacidades discursivas de João, ou seja, das capacidades de linguagem relacionadas ao reconhecimento da arquitetura textual do gênero.

Quanto aos aspectos de textualização/elementos linguísticos e gramaticais mobilizados, é possível constatar que as duas produções de João apresentam coerência e coesão, com poucos problemas de ortografia, mas a produção final (Figura 3) apresenta-se com um melhor alinhamento da escrita, com espaçamentos mais nítidos entre as palavras e as partes principais do texto (ele pula uma linha, embora marcando com um X), fazendo uso adequado da acentuação de palavras. Ainda que essa produção não apresente o espaço de adentramento dos parágrafos e nem pontuação (o ponto final e de interrogação aparecem na primeira produção), é possível verificar avanços nas capacidades linguístico-discursivas de João, inclusive com marcas de autoria mais evidentes, por exemplo: POR FAVOR FAÇA UM LIVRO DE AÇÃO, AVENTURA, TERROR, ANIVERSSÁRIO E MUITO MAIS/ SOU SEU FÃ NÚMERO 10. Nesses trechos percebemos que o aluno assume uma posição responsiva, tornando visível o seu dizer, pois escolheu as melhores palavras, a ordem dos fatos para interagir com o seu interlocutor.

Em síntese, com esta análise, podemos verificar que João demonstrou muitos avanços em suas capacidades de linguagem na produção final da carta ao autor: produziu um texto adequado à situação de comunicação proposta, buscando adaptar-se às características do contexto tal como foi solicitado na consigna, isto é, estabelecendo uma interação social real com o autor por meio da carta, mobilizando características típicas do gênero com linguagem 
adequada. Certamente, o trabalho desenvolvido nos módulos da SD, elaborados em função da avaliação diagnóstica da primeira produção, contribuiu para uma melhor aprendizagem dos alunos.

Tais resultados sinalizam que o trabalho com a SD no contexto da alfabetização contribui efetivamente no desenvolvimento das capacidades de linguagem do aprendiz, na medida em que lhe dá condições de sentir-se mais confiante ao produzir seus textos e, assim, ocupar um lugar de autor em condições de produção significativas.

\section{CONSIDERAÇÕES FINAIS}

Neste artigo, descrevemos e analisamos dados de uma pesquisa mais ampla em que buscamos analisar o processo de construção de uma SD com o gênero "carta ao autor", em uma turma de 1‥ ano, com vistas ao desenvolvimento das capacidades de linguagem dos aprendizes.

Os resultados da análise dos dados que consideramos neste trabalho apontam a relevância do dispositivo didático da SD para potencializar a aprendizagem dos alunos no contexto da alfabetização, pois constatamos, na produção final da carta ao autor, uma ampliação das capacidades de linguagem dos alunos.

Nesse sentido, defendemos que o trabalho com a SD de gêneros textuais é essencial na alfabetização, pois permite aos alunos e professores assumirem de melhor forma seus papéis. Para o professor dá maior autoria docente e fornece melhores instrumentos de avaliação das capacidades reais dos alunos, com um olhar mais refinado na elaboração das situações didáticas que ajudem os alunos a superarem as dificuldades localizadas em suas produções textuais, consequentemente, favorece o desenvolvimento profissional docente.

Para os alunos, o trabalho com a SD dá oportunidade de vivenciarem práticas de produção textual com propósitos claros e definidos, com melhores condições de produzirem textos autorais valorizando seu protagonismo e oportunidade de acompanharem seus próprios avanços, no uso da língua escrita em situações de aprendizagem significativas que contemplam a natureza social e dialógica da linguagem.

Enfim, o desenvolvimento do trabalho com a SD promoveu uma experiência aos alfabetizandos de produzir textos em situações reais, isto é, textos que realmente foram lidos pelo autor do livro e não apenas escritos para serem avaliados pela professora.

\section{REFERÊNCIAS}

APARICIO, A. S. M., ANDRADE, M. F. R. de. (2014). A formação de professores das séries iniciais do ensino fundamental: uma experiência com a engenharia didática e a construção de sequências didáticas de gêneros textuais do PIBID. In: APARÍCIO, A.S.M. \& SILVA, S.R. da. Gêneros textuais e perspectivas de ensino. Campinas: Pontes.

APARICIO, A. S. M., ANDRADE, M. F. R. de. (2016). A avaliação no processo de construção de sequências didáticas para o ensino da escrita nos anos iniciais do ensino fundamental: a formação do professor em foco. In: SILVA, S. R. da, FILHO, S. C.A. Sobre avaliação e ensino de línguas: (re)discutindo conceitos e (re)elaborando ações. Campinas: Pontes. 
BAKHTIN, M.(2003). Os gêneros do discurso. In: BAKHTIN, M. Estética da criação verbal. São Paulo: Martins Fontes, p.261-306.

BRASIL, Parâmetros curriculares nacionais: Língua Portuguesa. (1997). Brasília: Ministério da Educação.

BRASIL, Lei no 9394, de 20 de dezembro de 1996. (1996). Estabelece as diretrizes e bases da educação nacional. Diário Oficial da União, Brasília, DF, 23 dez. 1996.

COLELLO S. M. G.(2015). A escola e as condições de produção textual: conteúdos, formas e relações. 2015. 495 f. Tese (Livre docência) - Universidade de São Paulo, Faculdade de Educação, São Paulo, SP, Brasil.

COLELLO, S.M.G. (2014). Aprendizagem da língua escrita e a constituição do sujeito interlocutivo. In: International Studies on Law and Education 18 set. - dez. 2014.

DAMIANI, M. F., ROCHEFORT, Renato S.; CASTRO, Rafael Fonseca; DARIZ, Marion R.; PINHEIRO, S. N. S.(2013). Discutindo pesquisas do tipo intervenção pedagógica. Cadernos de Educação (UFPel), v. 45, p. 57-67.

DOLZ, J. , GAGNON, R. , DECÂNDIO, F. R. (2010). Produção escrita e dificuldades de aprendizagem. Campinas: Mercado de Letras.

DOLZ J. , NOVERRAZ, M., SCHNEUWLY, B.(2004). Sequências didáticas para o oral e a escrita: apresentação de um procedimento. In: SCHNEULWY, B; DOLZ, J. et al. Gêneros orais e escritos na escola. Campinas: Mercado de Letras.

GONÇALVES, A. V. Ferramentas didáticas para o ensino de língua portuguesa: gêneros textuais, transposição e modelo didáticos. (2008). Raído, Dourados, MS, v. 2, n. 4, p. 43-60.

LERNER, D. O. (2002). Ler e Escrever na Escola: o real, o possível e o imaginário. (E. Rosa, Trad.). Porto Alegre: Artmed, 2002.

LORO, Marcelo. (2016). Tutuli em: Que barulho é esse papai? São Paulo.

MACHADO, A.R. (2009). Linguagem e educação. O trabalho do professor em uma nova perspectiva. São Paulo: Mercado de Letras.

NASCIMENTO, E. L. (2014). Uma disciplina emergente: a didática das línguas. In: NASCIMENTO, E.L (org.). Gêneros Textuais: da didática das línguas aos objetos de ensino. São Paulo, SP: Pontes, p.21-50.

SOARES, M. (1999). “Aprender a escrever, ensinar a escrever". In: ZACCUR, E. (org.) A magia da linguagem. Rio de Janeiro: DP\&A/SEPE.

TEBEROSKY, A. COLOMER, T. (2003). Aprender a ler e a escrever: uma proposta construtivista. Porto Alegre: Artmed. 